\title{
Computer-aided instruction in a physiological psychology course
}

\author{
ELLEN F. ROSEN \\ College of William and Mary, Williamsburg, Virginia \\ and \\ LINDA C. PETTY \\ Hampton University, Hampton, Virginia
}

\begin{abstract}
A simulation/tutorial sequence was introduced into an undergraduate physiological psychology class $(N=32)$ to provide a laboratory experience. The college computer center managed the IBM-PC-compatible networked facility. The sequence included neuroanatomy, stereotaxic surgery, histology, electrical self-stimulation, and use of the polygraph. All the software was off the shelf except for the stereotaxic surgery/histology/self-stimulation package, which was written by the authors using ToolBook running under Windows.
\end{abstract}

Twenty-five years ago, physiological psychology at the undergraduate level at William and Mary was a small course of only about 9 students. Every student took the laboratory portion of the course. Students learned to use a stereotaxic instrument to implant a bipolar self-stimulation electrode in a rodent hypothalamus and to conduct a 2 subject self-stimulation experiment, did a sheep-brain dissection, and did a project using a polygraph. Today, there are often 40 students in the lecture, and since the laboratory can only accommodate a small fraction of that number, the laboratory section is an optional one-credit course. This growth is a reflection of the nationwide student increase in interest in psychology (Eckerman, 1991).

Over the last decade, the authors, along with many others, have changed their understanding of the relationship between humans and animals. Many laboratory students are no longer comfortable with even noninvasive laboratory work with animals, such as operant conditioning studies (Staley \& Rosen, 1992), much less surgery and histology.

Economically, it has become too expensive to conduct an old-fashioned laboratory class for all students. However, physiological psychology cannot truly be appreciated without some "hands-on" laboratory experiences.

Fortunately, some good software already exists that can be easily incorporated into such an experience. These are Brainscape (Wilson \& Ostergren, 1986), an adventuretype neuroanatomy lesson, and the Brain Localization and Sleep and Waking programs from the PsychWorld series (McGraw-Hill, 1990).

This project was supported by a grant to the College of William and Mary from the Funds for Excellence Program. L. C. Petty is with the Center for Teaching Excellence at Hampton University. Requests for reprints should be sent to E. F. Rosen, Department of Psychology, College of William and Mary, P.O. Box 8795, Williamsburg, VA $23187-8795$
In a graduate-level physiological psychology course with a neuropsychology emphasis taught this past spring, Life and Death II: The Brain (Software Toolworks, 1991) was used. It provides an opportunity to administer an abbreviated neurological examination to several types of patients with neurological disorders (Ehrenman, 1991). It also provides a simulation of human brain surgery in which considerable skill is necessary to avoid patient death. Students complained that the surgery was too difficult and reported that they were upset by the usual death of the surgery patients. The emotional arousal in response to the surgery aspect distracted from the objective for which the program was used, so it was decided not to include it in the undergraduate course.

In its completed form, the simulation laboratory sequence provides computer experiences aimed at developing an understanding of neuroanatomy, animai stereotaxic surgery, and electrical self-stimulation of the brain, and offers a polygraph experience. The neuroanatomy sequence includes the program Brainscape and the Brain Localization unit from the McGraw-Hill PsychWorld series. Students are required to complete worksheets for Brain Localization in which they report the results of their exploration of the brain. For Brainscape students are required to turn in a screen dump that shows that they have achieved a score of at least 500 out of the possible 1,150 . The neuroanatomy computer work is introduced by a class lecture that uses a series of brain transparencies and a large brain model. Additionally, a PC/AT and projection screen are used in class to show students how to use the programs.

According to a United States Department of Agriculture publication (Engler, 1989), there are no computer simulations of animal surgery suitable for our course. Thus, the authors wrote a program to simulate the rodent stereotaxic surgery and self-stimulation unit. This program is written using ToolBook 1.5 (Asymetrix, 1990) for Windows 3.0 (Microsoft, 1990). ToolBook is very similar to 
HyperCard in that it is a hypertext language that uses icons to allow students to control the flow of the program. According to Heerman (1988), this is important for making learning interesting for students with diverse cognitive styles. Initially, the program describes the use of the stereotaxic instrument and the stereotaxic atlas using graphics and scanned images and instructs the student on the implantation of electrodes in either the posterior or lateral hypothalamus of a laboratory rat. The student then is introduced to the self-stimulation apparatus and observes the self-stimulation behavior of the animal under two different levels of food deprivation ( 0 or $24 \mathrm{~h}$ ). Research indicates that adding food deprivation will increase the rate of self-stimulation of animals with electrodes in the lateral hypothalamus but not of animals with electrodes in the posterior hypothalamus. Students obtain data from simulated rats, one with electrodes in the posterior and one with electrodes in the lateral, each tested under both ad-lib and food-deprived conditions. Histologic procedures are then presented, and students are provided an outline for a short APA-style paper. The computer laboratory work is introduced with a slide and audiotape presentation on implanting stimulation electrodes with the stereotaxic instrument (Life Sciences Associates, 1979).

The third unit uses the Sleep unit from the PsychWorld II series. This simulation shows a person sleeping and presents the ongoing EEG. The student may wake the sleeper at any time, and the sleeper (a male) tells what he was dreaming. Students are led through an experiment on sleep and dreams and develop an outline for a short paper about the experiment. The computer work is preceded by an in-class demonstration of the polygraph using a Grass Model 7 and a student from the class as a subject. The demonstration includes recording heart rate and GSR.

The students who are concurrently enrolled in an optional laboratory section are excused from the computer work. They experience the introductory lectures but then do actual laboratory work instead of the computer simulations. These students provide a basis for comparison of laboratory and computer-simulation experiences. No direct comparison can be made of the stereotaxic unit, however, since ethical considerations restrict the "real" laboratory work to a drug study.

The computer simulations are made available in the microcomputer laboratory in the psychology building. The PCs are networked, and the software is placed on the network server. The college's Computer Center is responsible for the maintenance of the facility and of all equipment and software. The first author has the responsibility for putting the simulation packages onto the server. The PC lab has about 15 stations and is used primarily for psychology courses. The computer in the physiological laboratory is available only for students enrolled in the optional lab. It is used primarily for data collection for polygraph work.

\section{OUTCOME DATA}

Data are available on the first unit. Students in the laboratory portion of the course completed their sheep-brain dissection and brain-model work prior to the midterm examination. The other students in the class completed the Brainscape and Brain Localization programs prior to the midterm. The students spent an average of $86 \mathrm{~min}$ on Brain Localization and $232 \mathrm{~min}$ on Brainscape. They rated the Brain Localization program much higher, 66 versus $50[t(18)=2.57, p<.02]$ on a 100-point scale where 50 is "learned something worthwhile and the program held your attention." On a Likert-type scale where 1 was "very valuable" and 7 "very valueless," the students rated Brain Localization as more valuable than Brainscape, 2.7 versus $3.5[t(18)=2.03, p<.05]$. Positive comments about Brain Localization included that it let students go at their own pace, it held their interest, and the concepts presented were easy to understand. The students suggested that more graphics would be helpful, and they wanted the program to present more information. Brainscape, they asserted, definitely needed some kind of graphical representation. They had difficulty with the program because our computers are 16-MHz 386SXs and the software ran too fast even at the slow speed setting. They reported being frustrated by the program, and several students felt that the program required too much initial knowledge. Students who liked the game format found the program addictive, while those who disliked computer games disliked the program.

The midterm examination contained three neuroanatomy figures; students were to label them and indicate the functions of the structures. There were 8 students in the optional laboratory and 22 students in the computer simulation. There was no significant difference between the two groups of students on either the anatomy subscore of the test [ 23 vs. $28, t(28)=1.54$, lab vs. computer simulations] or on the remainder of the test [ $43 \mathrm{vs} .48, t(28)$ $=0.94]$.

On the basis of these results, we are convinced that the computer-simulation experience was worthwhile for the students. The students reported feeling that the programs were a useful experience. The knowledge of anatomy demonstrated on the midterm examination was as good as that of students who actually dissected a sheep brain. Because of the extreme negative feedback from some students toward Brainscape, in the future that program will be offered as an option.

\section{AVAILABILITY}

All of the programs are available for IBM PC compatibles. Brain Localization is a unit from the original PsychWorld series from McGraw-Hill. Sleep and Waking is also from McGraw-Hill but is part of the revised version, 
PsychWorld II. Both require at least a CGA display. Brainscape is a public-domain software program and can be obtained from Reasonable Solutions (2101 West Main, Medford, OR 97501; Disk No. 1819). It is a text-based program that has no graphics. The programs we developed require ToolBook 1.5, which runs under Windows 3.0. A run-time-only version of ToolBook 1.5 is available as shareware from Public Brand Software (P.O. Box 51315, Indianapolis, IN 46251; Disks UX50a.1, UX50b.1, and UX50c.1). Copies of the two book files that make up the stereotaxic/electrical stimulation module can be obtained by sending a formatted high-density disk (either 3.5- or 5.25-in.) and a self-addressed mailing label to the first author.

\section{REFERENCES}

Asymetrix (1990). ToolBook. Bellevue, WA: Author.

ECKerman, D. A. (1991). Microcomputers in undergraduate labora- tory training in psychology. Behavior Research Methods, Instruments, \& Computers, 23, 91-99.

Ehrenman, G. C. (1991, September 10). Life and death II tests amateur brain surgeons. PC Magazine, p. 543.

ENGLER, A. (1989). Animal-related computer simulation programs for use in education and research. Washington, D.C.: United States Department of Agriculture.

Heermann, B. (1988). Teaching and learning with computers. San Francisco: Jossey-Bass.

LiFE SCIENCE Associates (1979). Electrical self-stimulation of the rat brain. New York: Author.

McGraw-Hill (1990). PsychWorld II. New York: Author.

Microsoft (1990). Windows 3.0. Redmond, WA: Author.

SOFTWARE ToOLWORKs (1991). Life \& death II: The brain. Novato, CA: Author.

Staley, R., Rosen, E. (1992, April). Recycling" rats in the experimental psychology laboratory course. Paper presented at the meeting of the Eastern Psychological Association, Boston.

Wilson, W. J., Ostergren, L. A. (1986). BRAINSCAPE! A Pascal adventure in neuroanatomy for IBM-PCs and compatibles. Behavior Research Methods, Instruments, \& Computers, 18, 478. 479. 